\title{
Erratum
}

\section{Dopamine and serotonin metabolism in response to chronic administration of fluvoxamine and haloperidol combined treatment}

\author{
Y. Chertkow ${ }^{1,2}$, O. Weinreb ${ }^{2}$, M. B. H. Youdim ${ }^{2}$, H. Silver ${ }^{1}$ \\ [J Neural Transm DOI 10.1007/s00702-007-0753-1]
}

The original version of this paper unfortunately contained a mistake: in Introduction, page 1, second column, 6 . to last line, the word 'not' should be omitted.

The correct sentence is: "The augmenting effect is associated with the serotonergic system since maprotaline, an equally effective nonserotonergic antidepressant, did not improve negative symptoms (Silver and Shmugliakov 1998)."

Authors apologize for the error. 